\title{
Longitudinal peak strain detects a smaller risk area than visual assessment of wall motion in acute myocardial infarction
}

\author{
Lene Rosendahl $1^{1,2^{*}}$, Peter Blomstrand ${ }^{1}$, Lars Brudin ${ }^{3,4}$, Tim Tödt ${ }^{5}$, Jan E Engvall ${ }^{2,6}$
}

\begin{abstract}
Background: Opening of an occluded infarct related artery reduces infarct size and improves survival in acute STelevation myocardial infarction (STEMI). In this study we performed tissue Doppler analysis (peak strain, displacement, mitral annular movement (MAM)) and compared with visual assessment for the study of the correlation of measurements of global, regional and segmental function with final infarct size and transmurality. In addition, myocardial risk area was determined and a prediction sought for the development of infarct transmurality $\geq 50 \%$.

Methods: Twenty six patients with STEMI submitted for primary percutaneous coronary intervention (PCI) were examined with echocardiography on the catheterization table. Four to eight weeks later repeat echocardiography was performed for reassessment of function and magnetic resonance imaging for the determination of final infarct size and transmurality.

Results: On a global level, wall motion score index (WMSI), ejection fraction (EF), strain, and displacement all showed significant differences $(p \leq 0.001, p \leq 0.001, p \leq 0.001$ and $p=0.03$ ) between the two study visits, but MAM did not $(p=0.17)$. On all levels (global, regional and segmental) and both pre- and post PCI, WMSI showed a higher correlation with scar transmurality compared to strain. We found that both strain and WMSI predicted the development of scar transmurality $\geq 50 \%$, but strain added no significant information to that obtained with WMSI in a logistic regression analysis.
\end{abstract}

Conclusions: In patients with acute STEMI, WMSI, EF, strain, and displacement showed significant changes between the pre- and post PCI exam. In a ROC-analysis, strain had 64\% sensitivity at $80 \%$ specificity and WMSI around $90 \%$ sensitivity at $80 \%$ specificity for the detection of scar with transmurality $\geq 50 \%$ at follow-up.

\section{Background}

The treatment of acute myocardial infarction has undergone dramatic changes in the last decade. For ST-elevation myocardial infarction (STEMI), mechanical opening of the infarct related artery has gained widespread acceptance and the health care systems in many countries have adopted this policy for proper care of STEMI. Several studies have shown that short time to primary percutaneous coronary intervention (PCI) in patients with myocardial infarction reduces mortality [1-4], is associated with a high degree of myocardial salvage [5]

\footnotetext{
* Correspondence: lene.rosendahl@lj.se
'Department of Clinical Physiology, Ryhov County Hospital, Jönköping,

* Correspondence: lene.rosendah|@lj.se
'Department of Clinical Physiology, Ryhov County Hospital, Jönköping, Sweden
}

(c) 2010 Rosendahl et al; licensee BioMed Central Ltd. This is an Open Access article distributed under the terms of the Creative Commons Attribution License (http://creativecommons.org/licenses/by/2.0), which permits unrestricted use, distribution, and reproduction in any medium, provided the original work is properly cited.

and improves the procedural success rate of PCI, the functional recovery of the left ventricle and the clinical outcome [6]. Myocardium at risk, collateral flow, and duration of coronary occlusion are each independently associated with final infarct size [7] and the myocardial salvage achieved by reperfusion therapy in patients with acute myocardial infarction has a prognostic value for clinical outcome [8].

Research has tried to elucidate the relative importance of various time delays [3,9-11], different ways to protect ischemic myocardium as well as to find methods to predict the chance for success in infarct limiting therapies [12]. Such methods have relied on echo wall motion, echo measurements of deformation, scintigraphic signs of preserved myocardial blood flow as well as newer 
imaging methods such as gadolinium based visualization of micro vascular obstruction or oedema sensitive imaging of myocardial area at risk.

Echo wall motion analysis of myocardial ischemia is built on the concept that ischemia and scar confer a reduction in wall thickening and in longitudinal wall displacement and induce a delay in the onset of myocardial contraction. Various methods have been suggested for objective measurement of wall motion abnormalities $[13,14]$ and experiments have been designed to measure the smallest temporal changes that the human eye can detect [15]. Strain $(\varepsilon)$ expresses the local deformation of contracting muscle [16-18]. It is a complicated measure that requires 9 tensor values to adequately describe motion in all directions. Simplified solutions are those that determine strain along the tissue Doppler beam (1dimensional) or from speckle in the gray scale image (2D-strain, 2-dimensional). 2D or 3D strain can also be calculated from tag lines introduced in cardiac tissue at a cardiac magnetic resonance imaging (MRI) exam. Strain appears to be less affected by global cardiac motion and the tethering effect of adjacent myocardial segments than myocardial velocities [19]. Normal $\varepsilon$ values for a group of healthy adults have been defined [20]. Strain has been shown to quantify the severity of myocardial segmental dysfunction $[21,22]$ as well as predict the recovery of regional wall motion in patients with acute myocardial infarction subjected to PCI [23]. For patients with acute myocardial ischemia, an ultrasonic strain index $((\varepsilon$ peak $-\varepsilon$ systole $) / \varepsilon$ peak $)$ has been suggested for the differentiation of acutely ischemic segments from both normal and chronically dysfunctional myocardium [24]. However, despite being less sensitive to influences from neighbouring segments, the wide variation in reference values [20] has seriously hampered the use of these measurements for individual prediction in clinical practice.

Late gadolinium enhancement (LGE) MRI accurately determines infarct size [25] and has a high reproducibility [26]. A high spatial resolution enables measuring infarct transmurality and from this parameter the assessment of viable myocardium is possible [27-29].

In this study, we performed echocardiography with tissue Doppler imaging simultaneously with primary PCI, on the catheterization table, to determine myocardial area at risk and to study whether wall motion score index (WMSI) and tissue Doppler parameters correlated globally, regionally and segmentally with the size of the final scar and its transmurality.

\section{Methods}

\section{Study Population}

Twenty-six patients $(23$ men) average age $65 \pm 8$ years (range $50-78$ ), table 1, were selected for this analysis from among 99 patients included in a study of primary PCI for ST-elevation myocardial infarction, from February 2006 to August 2007. The patients agreed to have acute echocardiography performed immediately as they were prepared for acute coronary intervention and on their return 4-8 weeks later for the determination of infarct size with MRI. Exclusion criteria were a new myocardial infarction (MI) and the need for rapid coronary artery bypass graft (CABG) surgery or renewed PCI during the interim period between primary discharge and the MRI. In the main study 159 patients were included and 99 finally completed the investigations. Acute echocardiography was possible only during office hours, enabling the inclusion of 26 patients for the echo substudy. All patients underwent coronary angiography with balloon dilatation and most frequently stenting, via a standard femoral approach. The culprit lesion was located in the left anterior descending coronary artery system (LAD) in 15 patients, in the right coronary artery (RCA) in 9 and in the left circumflex artery $(\mathrm{CX})$ in 2 patients, table 1 . Additional stenoses not dilated at the index event were seen in 10 of the 26 patients.

Approval was obtained from the Regional ethical review board in Linköping. The study complied with the Declaration of Helsinki and with agreements on Good Clinical Practice. All patients gave written informed consent.

\section{Table 1 Patient characteristics}

\begin{tabular}{ll}
\hline & Parameter \\
\hline Age (Yrs; mean (SD) range) & $65.3(7.9) 50-78$ \\
Gender & $23(88)$ \\
$\quad$ Males ( $;$; \%) & $3(12)$ \\
Females (n; \%) & $178(9)$ 157-195 \\
Height (cm; mean (SD) range) & $83(9) 58-102$ \\
Weight (kg; mean (SD) range) & $26.2(3.3) 21-37$ \\
BMI (mean (SD) range) & $3(12)$ \\
Prior myocardial infarction & $23(88)$ \\
$\quad$ Yes (n; \%) & $15(58)$ \\
No (n; \%) & $9(35)$ \\
Culprit coronary artery (angio) & $2(8)$ \\
LAD (n; \%) & \\
RCA (n; \%) & $2(8)$ \\
CX (n; \%) & $9(35)$ \\
MI (extent) & $15(58)$ \\
No Ml & Subendocardial (n; \%)
\end{tabular}

$\mathrm{BMI}=$ body mass index, $\mathrm{LAD}=$ left anterior descending coronary artery, RCA $=$ right coronary artery, $\mathrm{CX}=$ left circumflex coronary artery, $\mathrm{MI}=$ myocardial infarction 


\section{Echocardiography}

At least three apical views were obtained with tissue Doppler (two-beat loops) while the patient was draped and prepared for acute PCI (GE V7 or GE V5 with 3 $\mathrm{MHz}$ transducers using harmonic imaging technology). At follow-up, a minimum of three apical loops were recorded, preferably in end expiration to minimize translational movement of the heart. The left ventricle was divided into 16 segments ( 6 basal, $6 \mathrm{mid}$, and 4 apical) [30]. The myocardial motion of each segment was evaluated according to the standard American Society of Echocardiography wall motion scoring system and WMSI was calculated $[30,31]$ (additional file 1). The three observers were blinded as to the temporal order of the echocardiographic investigations as well as to the result of the determination of transmurality.

Tissue Doppler images were acquired with a framerate exceeding 90/s. Off-line analysis was performed using Echopac software (Echopac BT08, GE Vingmed Ultrasound, Norway). In each of the three apical views, six segments were defined and regions of interest (ROI) using sample volumes of $6 \times 12 \mathrm{~mm}$ were applied. Tissue Doppler values in the apical anteroseptal and inferoseptal segments were averaged into an apical septal segment and in the anterolateral and inferolateral averaged into an apical lateral segment thus allowing conversion from 18 segments into a 16 segment model. After checking for aliasing in the velocity mode, myocardial strain and displacement curves were drawn and the peak values, regardless of delay time, were measured on two consecutive beats, if possible (figure 1, additional file 2). Peak systolic strain was calculated from the velocity determination in the longitudinal direction. Normal shortening strain was denoted with negative values while lengthening was assigned positive values. Displacement from the base towards the apex was given negative values and displacement towards the base positive values [32] (additional file 3). Long axis left ventricular function was assessed from mitral annular motion (MAM) which was measured in four positions on the mitral annular ring. Values for strain, displacement and MAM were obtained by two observers and their average was calculated. The reference values for longitudinal strain by Kowalski et.al. $(-16 \% \pm 5 \%)$ were used as cut-off [20]. Left ventricular ejection fraction was calculated using the biplane Simpson's method of discs and averaged from two consecutive heart beats in exams with sufficient image quality.

To obtain global measurements of wall motion and strain, measurements from each segment were added and the sum divided by the total numbers of segments. To assess regional measurements of wall motion and strain in relation to infarct transmurality, numbers for the three segments of each wall (anterior, lateral, posterior and septal) were averaged.

\section{Magnetic resonance imaging}

The patients were placed in the magnet (1.5 T Achieva, Philips Healthcare, Best, The Netherlands) in supine position. A circular polarized body-array surface coil was used in all measurements. ECG-triggered MR images were obtained during repeated breath-holds.

Cine-MR imaging was performed with a balanced steady state free precession turbo field-echo (b-SSFP TFE) sequence that covered the entire left ventricle with on average 18 (range 10 - 23) short-axis slices and three long axis planes (apical 2-, 3- and 4-chamber views). Temporal resolution ranged between $26-41 \mathrm{~ms}$ (30 acquired phases). The inversion recovery turbo field echo (IR-TFE) sequence was a segmented 3D spoiled gradient echo sequence with $\mathrm{TE}=1.3 \mathrm{~ms}$, $\mathrm{TR}=4.4 \mathrm{~ms}$ and TFE factor 43, leading to an acquisition phase time of $188 \mathrm{~ms}$ acquired during diastole. Slice thickness was $10 \mathrm{~mm}$, intersection gap $-5 \mathrm{~mm}$ (i.e. slices were overcontiguous), field-of-view $350 \mathrm{~mm}$ and image matrix $128 \times 256$. The contrast-enhanced images were acquired at the same slice positions as the cine-images, about 20 min after the administration of gadopentetate dimeglumine (Gd-DTPA) $0.2 \mathrm{mmol} / \mathrm{kg}$ bodyweight (Schering Nordiska AB, Järfälla, Sweden). Optimal contrast between hyperenhanced areas and normal myocardium was maintained by continually adjusting the inversion time to null the signal from the healthy myocardium.

Scar size was measured by two different observers on short-axis images using a freely available software "Segment" http://segment.heiberg.se, [33]. Infarct volume and percentage was calculated from the short axis stack of slices (scar area $\times$ thickness $\times$ number of slices) and was averaged for the two observers. Infarct transmurality per segment was in this setting determined in the three apical views by using "Segment" and defined as segmental scar area (6 segments per view, figure 2$)$. The 18 segments were reduced to 16 segments, identical to those used in the tissue Doppler analysis. Enddiastolic myocardial and cavity volumes were measured from the short axis LGE images (segmented myocardial or cavity area $\times$ thickness $\times$ number of slices). Myocardial mass (gram) was obtained by multiplying volume (ml) by 1.05

\section{Data analysis and statistics}

All heart-related parameters were reasonably well normally distributed and presented as mean $\pm(\mathrm{SD})$. The difference on global level between pre- and post PCI exams was analysed by two-sided t-test for paired observations. Spearman's rank correlation was used for global-, regional-, and segmental functional parameters vs. infarct size and infarct transmurality. The difference between normal segments (transmurality $<1 \%$ ) and 


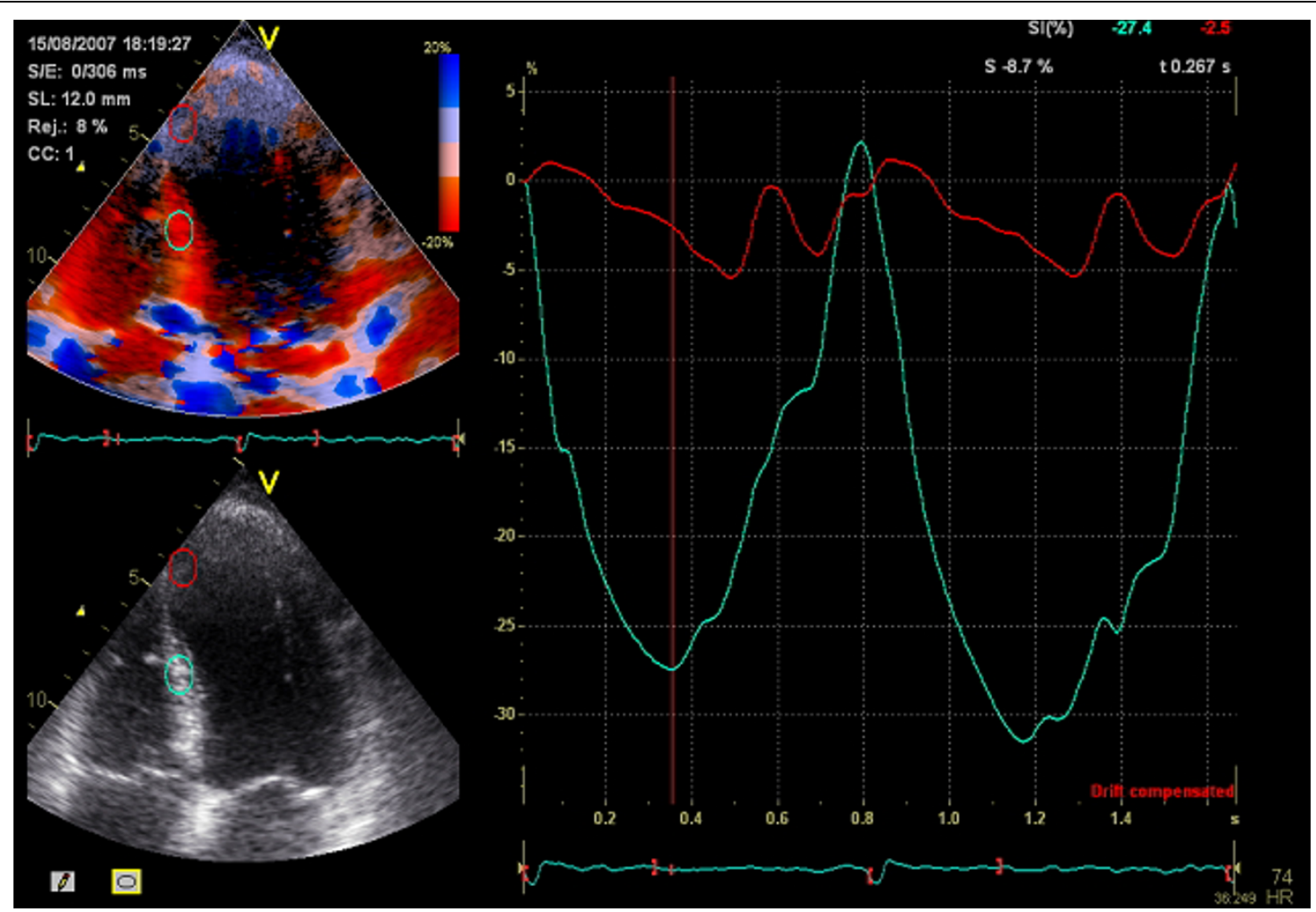

Figure 1 Strain curves from the septum at follow-up. Blue: normal longitudinal strain curve recorded from healthy myocardium in the middle septal segment. Red: reduced longitudinal strain in thinned, infarcted myocardium of the apical septal segment.

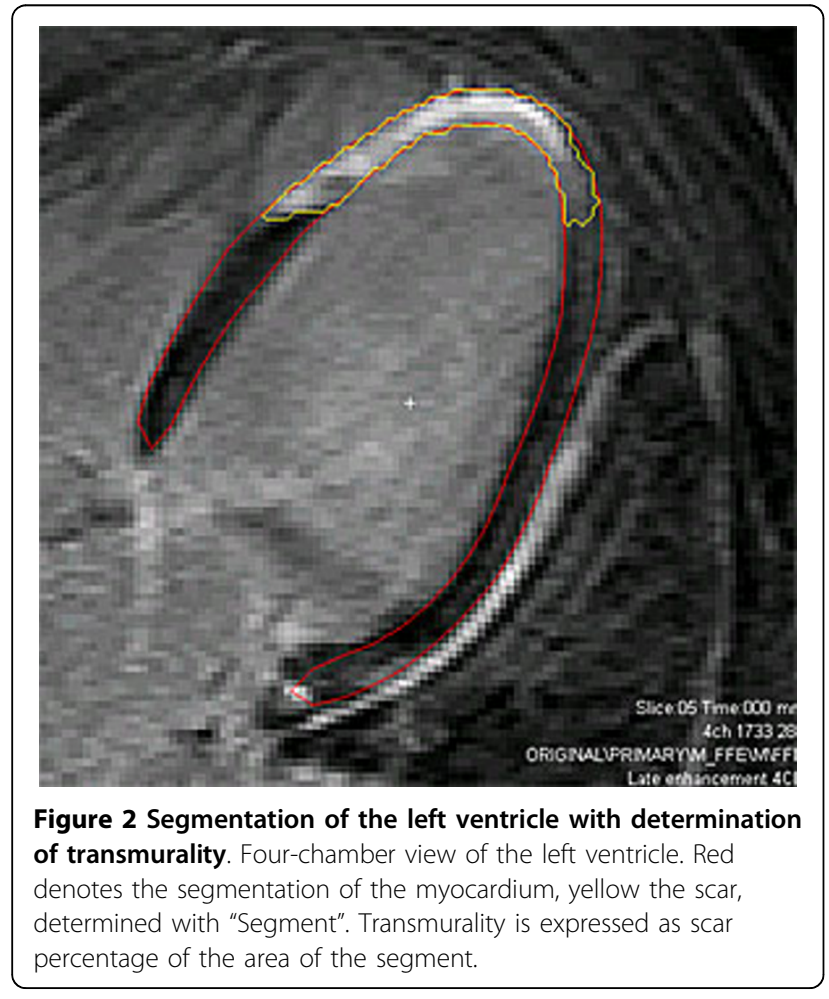

segments with transmurality $\geq 50 \%$ on regional level was analyzed with Mann-Whitney's U-test. Receiver-operator-characteristics (ROC) curve analyses were performed using the statistical software MedCalc ${ }^{\bullet}$ Version 6.10 (MedCalc Software, Mariakerke, Belgium). The interaction between WMSI and strain on the detection of segments with a transmurality $\geq 50 \%$ was analysed with logistic regression.

Interobserver variability of the functional measures was expressed as standard error of a single determination $\left(\mathrm{S}_{\text {method }}\right)$ using the formula, first proposed by Dahlberg [34], $S_{\text {method }}=\sqrt{ }\left(\sum \mathrm{d}_{\mathrm{i}}{ }^{2} /(2 \mathrm{n})\right)$, where $\mathrm{d}_{\mathrm{i}}$ is the difference between the i:th paired measurement and $n$ is the number of differences. $S_{\text {method }}$ was also expressed as $\%$ over all means when applicable.

Analyses were performed using SPSS 13.0 (SPSS Inc, Chicago, Illinois). Two-tailed $P$ values were used, with $\mathrm{p}$ $\leq 0.05$ considered to indicate statistical significance.

\section{Results}

\section{Global left ventricular measures}

Left ventricular myocardial volume was $167.8 \pm 36.9 \mathrm{ml}$ (range $88-254 \mathrm{ml}$ ). Infarct size, determined at followup 4 - 8 weeks after PCI, was on average $( \pm$ SD) $14.9 \pm$ 
$5.6 \mathrm{ml}(8.7 \pm 7.4 \%$ of the volume of the left ventricular myocardium). Mean transmurality of affected segments was calculated for each of the 24 patients with followup scars $\geq 1 \%$, giving a patient average of $44.3 \pm 18.0 \%$ (range 8.5 - 76). At follow-up, WMSI improved from an average $( \pm \mathrm{SD})$ of $1.6 \pm 0.3$ to $1.4 \pm 0.3(\mathrm{n}=26$; $\mathrm{p}=$ 0.001).

Corresponding numbers for ejection fraction were $38.5 \pm 8.5 \%$ to $46.8 \pm 8.5 \%(\mathrm{n}=17 ; \mathrm{p}=0.001)$ and for global strain $-13.2 \pm 3.3 \%$ to $-15.7 \pm 3.5 \%(n=26 ; p<$ $0.001)$. Displacement changed from $-5.4 \pm 1.8 \mathrm{~mm}$ to $-6.1 \pm 1.4 \mathrm{~mm}(\mathrm{n}=26 ; \mathrm{p}=0.030)$. The change in MAM did not reach statistical significance (mean $10.5 \pm 2.7$ $\mathrm{mm}$ to $11.1 \pm 2.3 \mathrm{~mm} ; \mathrm{n}=26 ; \mathrm{p}=0.167)$.

There were statistically significant correlations between infarct size and percent transmurality post-PCI (assessed by MRI) on the one hand and systolic ultrasonic measures pre and post PCI on the other (table 2). The highest correlation was for WMSI post PCI vs. infarct size $(r=0.83)$ and for WMSI post PCI and transmurality $(r=0.88)$, but also global strain post PCI correlated with infarct size $(r=0.51)$ and with transmurality $(r=0.64)$. Individual functional global measures pre- and post-PCI, ranked after scar size postPCI, are shown in figure 3.

\section{Regional ventricular measures}

Wall motion score correlated moderately with transmurality in the acute phase and at follow-up ( $\mathrm{r}=0.67, \mathrm{p}<$ 0.001 and $r=0.63, p<0.001)$ while the correlation for longitudinal strain vs. transmurality was lower at both time points $(\mathrm{r}=0.51, \mathrm{p}<0.001$ and $\mathrm{r}=0.44 \mathrm{p}<0.001)$ and for MAM still lower $(\mathrm{r}=-0.25, \mathrm{p}=0.01$ and $\mathrm{r}=$ $-0.41, \mathrm{p}<0.001)$. In a comparison between walls with transmurality $\geq 50 \%$ and normal walls, WMSI, strain and MAM all displayed values that were significant. The change post-pre was not significant for any of the three measures, see table 3 .

\section{Segmental ventricular measures}

In the initial study, 390 out of 416 segments (94\%) were successfully visualised and at follow up 410 of the 416 segments (99\%). Wall motion score correlated moderately with transmurality in the acute phase and at followup $(\mathrm{r}=0.58, \mathrm{p}<0.01$ and $\mathrm{r}=0.53, \mathrm{p}<0.01)$ while longitudinal strain correlated weakly with transmurality at both time points $(\mathrm{r}=0.38, \mathrm{p}<0.01$ and $\mathrm{r}=0.31 \mathrm{p}<$ 0.01 ). Displacement, regardless of the position of the segment (apical-middle-basal) also correlated weakly with transmurality $(\mathrm{r}=0.28, \mathrm{p}<0.001$ and $\mathrm{r}=0.34, \mathrm{p}<0.001)$.

The segmental values were analysed from two approaches. One was based on the evaluation of WMSI (normal or abnormal) and transmurality in regard to strain for segments that either deteriorated, improved or remained unchanged between the acute event and followup (table 4). In the other approach, normal or reduced
Table 2 Spearman rank correlation of global functional parameters vs. infarct size and infarct transmurality

\begin{tabular}{cccc}
\hline Parameter & Infarct size & \multicolumn{2}{c}{ Transmurality (\%) } \\
\hline & Scar\% & All segments & $\begin{array}{c}\text { Affected } \\
\text { segments }\end{array}$ \\
Strain $(\varepsilon)$ & & & \\
Pre_PCl & $n=26 ; r=0.48 ;$ & $n=26 ; r=0.61 ;$ & $n=22 ; r=0.42 ;$ \\
& $p=0.014$ & $p=0.001$ & $p=0.054$ \\
Post-PCl & $n=26 ; r=0.51 ;$ & $n=26 ; r=0.64 ;$ & $n=22 ; r=0.44 ;$ \\
& $p=0.008$ & $p=<0.001$ & $p=0.042$ \\
MAM & & & \\
Pre_PCl & $n=26 ; r=-0.24 ;$ & $n=26 ; r=-0.39 ;$ & $n=22 ; r=-0.29 ;$ \\
& $p=0.245$ & $p=0.051$ & $p=0.198$ \\
Post-PCl & $n=26 ; r=-0.56 ;$ & $n=26 ; r=-0.61 ;$ & $n=22 ; r=-0.40 ;$ \\
& $p=0.003$ & $p=<0.001$ & $p=0.066$ \\
EF\% & & & \\
Pre_PCl & $n=18 ; r=-0.29 ;$ & $n=18 ; r=-0.52 ;$ & $n=16 ; r=-0.40 ;$ \\
& $p=0.238$ & $p=0.029$ & $p=0.121$ \\
Post-PCl & $n=24 ; r=-0.06 ;$ & $n=24 ; r=-0.18 ;$ & $n=20 ; r=-0.07 ;$ \\
& $p=0.790$ & $p=0.411$ & $p=0.757$ \\
WMSI & & & \\
Pre_PCl & $n=26 ; r=0.55 ;$ & $n=26 ; r=0.75 ;$ & $n=22 ; r=0.59 ;$ \\
& $p=0.003$ & $p=<0.001$ & $p=0.004$ \\
Post-PCl & $n=26 ; r=0.83 ;$ & $n=26 ; r=0.88 ;$ & $n=22 ; r=0.80 ;$ \\
& $p=<0.001$ & $p=<0.001$ & $p=<0.001$ \\
\hline
\end{tabular}

Spearman's rank correlations $(n ; r ; p)$ between global ultrasonic systolic measures pre and post $\mathrm{PCl}$ on the one hand and infarct size and transmurality post $\mathrm{PCl}$ on the other. Significant correlations are bolded.

strain was the watershed from which the level of transmurality and changes in WMSI were evaluated (table 5).

Myocardial area at risk

Initially, 231 out of 390 visible segments displayed wall motion abnormalities. 97 of these developed scar with transmurality $>1 \%$, i.e. final scar affected $42 \%$ of the segments at risk (table 4). Based on longitudinal strain > $-11 \%, 129$ segments were abnormal initially of which 60 developed scar with transmurality $>1 \%$, i.e. final scar affected $46 \%$ of the segments at risk (table 5 ). However, of the 261 segments that were determined to be normal according to strain < -11\%, 47 segments (18\%) developed scar compared to 10 segments (6\%) with WMSI. The two methods were compared in a ROC-analysis as for the prediction of segments that were to develop scar with a transmurality $\geq 50 \%$, figure 4 . AUC was significantly higher for WMSI (0.92) than for strain (0.78), p < 0.0001 . Sensitivity at $80 \%$ specificity was for strain $64 \%$ and for WMSI close to $90 \%$. In a logistic regression analysis incorporating WMSI and strain, both parameters were significant for the prediction of transmurality $\geq$ $50 \%$ but strain did not add significant information beyond that carried by WMSI.

Interobserver variability

The calculated error $\left(\mathrm{S}_{\text {method }}\right)$ between three observers were for WMSI 0.50 (coefficient of variation $(\mathrm{COV})=$ 

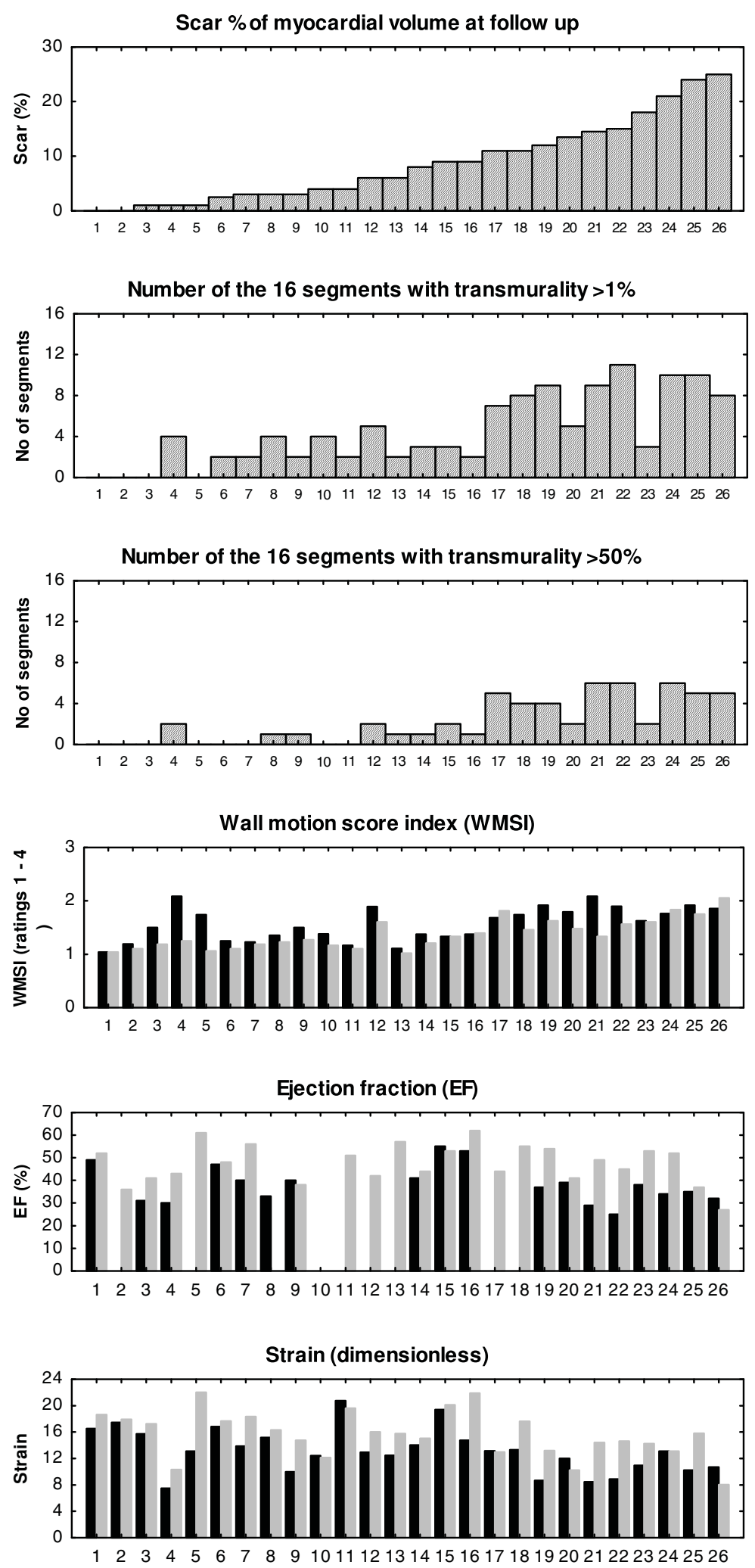

Figure 3 Composite display of infarct size and functional measures. Upper panel shows the distribution of scar percentage among the individual patients (no 1 to no 26). Next two panels show the number of segments with transmurality either $>1 \%$ or $>50 \%$ per patient. The three panels at the bottom show wall motion, ejection fraction and strain pre-PCl (black) and at follow-up (gray). 
Table 3 Regional analysis of wall motion score index

\begin{tabular}{|c|c|c|c|c|c|c|}
\hline & \multicolumn{6}{|c|}{ Transmurality post-PCI } \\
\hline & & Normal $(<1 \%)$ & $1-24 \%$ & $25-50 \%$ & $>50 \%$ & p-value* \\
\hline $\mathrm{n}=$ number of walls & & 50 & 28 & 11 & 15 & \\
\hline \multicolumn{7}{|c|}{ Transmurality (\%; mean) } \\
\hline Postop & $n=104$ & $0.0 \pm 0.1$ & $9.4 \pm 6.5$ & $36.3 \pm 7.4$ & $64.7 \pm 9.9$ & - \\
\hline \multicolumn{7}{|l|}{ WMSI (mean \pm SD) } \\
\hline Preop & $n=102$ & $1.3 \pm 0.4$ & $1.7 \pm 0.3$ & $1.9 \pm 0.2$ & $2.2 \pm 0.5$ & $p<0.001$ \\
\hline Postop & $n=104$ & $1.2 \pm 0.3$ & $1.4 \pm 0.4$ & $1.6 \pm 0.3$ & $1.9 \pm 0.2$ & $p<0.001$ \\
\hline$\Delta$ & $n=102$ & $-0.1 \pm 0.4$ & $-0.3 \pm 0.4$ & $-0.3 \pm 0.4$ & $-0.3 \pm 0.6$ & 0.330 \\
\hline \multicolumn{7}{|l|}{ Strain (mean \pm SD) } \\
\hline Preop & $n=102$ & $-15.3 \pm 4.9$ & $-10.5 \pm 3.6$ & $-10.9 \pm 4.5$ & $-8.4 \pm 6.3$ & $p<0.001$ \\
\hline Postop & $n=104$ & $-17.3 \pm 4.7$ & $-14.3 \pm 4.2$ & $-14.9 \pm 4.1$ & $-12.3 \pm 4.2$ & $p<0.001$ \\
\hline$\Delta$ & $n=102$ & $-2.0 \pm 5.8$ & $-4.2 \pm 4.6$ & $-4.0 \pm 3.7$ & $-4.0 \pm 5.0$ & 0.205 \\
\hline \multicolumn{7}{|c|}{ MAM $(m m ;$ mean $\pm S D)$} \\
\hline Preop & $\mathrm{n}=98$ & $11.4 \pm 2.9$ & $9.4 \pm 2.9$ & $10.7 \pm 3.0$ & $9.3 \pm 2.9$ & 0.027 \\
\hline Postop & $n=103$ & $12.2 \pm 2.6$ & $10.1 \pm 2.1$ & $11.6 \pm 2.1$ & $9.2 \pm 2.0$ & $p<0.001$ \\
\hline$\Delta$ & $\mathrm{n}=97$ & $0.8 \pm 2.9$ & $0.6 \pm 2.8$ & $1.4 \pm 3.0$ & $0.2 \pm 2.2$ & 0.706 \\
\hline
\end{tabular}

$32 \%)$ and $0.42(\mathrm{COV}=30 \%)$ calculated for the pre- and post-PCI investigations. Corresponding methodological errors for the two observers of the MAM were $1.30 \mathrm{~mm}$ $(12.4 \%)$ and $1.04(9.3 \%)$, respectively. The methodological error in absolute numbers was for strain pre-PCI 5.4 and for post-PCI 4.5. Corresponding values for displacement were 1.59 and 1.43 , respectively. COV for these measurements is of no interest since the values include zero. No significant differences were found, in regard to these measurements, between pre- and post PCI examinations. $S_{\text {method }}$ for scar assessed by MR post-PCI was $1.6 \mathrm{ml}(11 \%)$ or related to myocardial volume $1.1 \%$ (12\%).

\section{Discussion}

\section{Main findings of the study}

In this study we show that the initial evaluation based on visual assessment of wall motion as well as on objective measurements of wall deformation correlate with the final infarct size and transmurality at follow-up after 4 - 8 weeks. Functional evaluation based on echocardiography on the catheterization table seems valid, since those measurements correspond fairly well with assessments performed under less hurried conditions at follow-up. Prediction of segments/walls that will develop permanent scar is possible with both methods but visual assessment seems superior in this respect (figure 4). Visual wall motion assessment has been criticized because of its subjectivity [35] but was robust in the present study. Peak strain from myocardial tissue Doppler showed less correlation with final infarct size and transmurality than visual assessment, both in the acute study and in the quiet imaging conditions at follow-up.

\section{Global measurements}

Global strain reflects the averaged segmental myocardial long-axis relative shortening and is a global functional measurement that may give information beyond what is available from WMSI and left ventricular ejection fraction (LVEF) [36]. Strain is an objective measurement compared with the subjective evaluation of wall motion and might therefore be a valuable instrument in the daily workflow. However, we found that global strain showed a moderate correlation with total infarct size and mean transmurality, lower than that for WSMI. To the contrary, Gjesdal et.al. showed a higher correlation (0.84) between global strain and scar compared to WMSI and scar (0.70) in patients with chronic myocardial infarction [37]. In their study, 2D-speckle tracking echocardiography was used on somewhat younger patients (mean age 55 yrs) 9 months after MI. Additionally, Vartdal et. al found a correlation of 0.77 between strain and infarct size in patients with acute STEMI [38]. The corresponding figure for WMSI and infarct size was $r=0.45$. However, these patients were examined $1.5 \mathrm{~h}$ after revascularization when ischemic wall motion abnormalities could have declined, possibly faster than changes in strain. Interestingly, they also found that global strain might be a valuable predictor for the total amount of scar and hence might be a clinical tool for risk stratification. Recently, Gjesdal. et.al. showed a significant correlation between MAM, measured in 4 positions, and infarct size $(\mathrm{r}=0.58, \mathrm{p}<0.01)$ in patients 
Table 4 Segmental analysis of strain $(\varepsilon)$ pre and post $\mathrm{PCI}$ and transmurality post-PCI

\begin{tabular}{|c|c|c|c|c|c|}
\hline \multirow{2}{*}{$\begin{array}{l}\text { PrePCI WMSI } \\
\text { Follow-up WMSI }\end{array}$} & \multicolumn{2}{|c|}{ Normal } & \multicolumn{3}{|c|}{ Abnormal } \\
\hline & Deteriorated & Unchanged & Deteriorated & Unchanged & Improved \\
\hline $\mathrm{n}$ & 7 & 152 & 15 & 141 & 75 \\
\hline \multicolumn{6}{|l|}{ WMSI (mean \pm SD) } \\
\hline Preop & $1.0 \pm 0.0$ & $1.0 \pm 0.0$ & $1.6 \pm 0.4$ & $1.8 \pm 0.6$ & $2.3 \pm 0.5$ \\
\hline Postop & $1.7 \pm 0.2$ & $1.1 \pm 0.1$ & $2.3 \pm 0.4$ & $1.6 \pm 0.6$ & $1.3 \pm 0.5$ \\
\hline Post-pre-difference & $0.7 \pm 0.2$ & $0.1 \pm 0.1$ & $0.7 \pm 0.2$ & $-0.2 \pm 0.2$ & $-1.0 \pm 0.3$ \\
\hline \multicolumn{6}{|l|}{ Strain (mean \pm SD) } \\
\hline Preop & $-15.1 \pm 5.7$ & $-16.6 \pm 5.6$ & $-11.8 \pm 7.1$ & $-11.4 \pm 8.0$ & $-9.4 \pm 7.9$ \\
\hline Postop & $-16.6 \pm 5.2$ & $-17.4 \pm 5.2$ & $-13.4 \pm 8.1$ & $-15.0 \pm 7.7$ & $-14.3 \pm 6.8$ \\
\hline Post-pre-difference & $-1.5 \pm 5.1$ & $-0.8 \pm 6.5$ & $-1.6 \pm 3.7$ & $-3.7 \pm 7.3$ & $-4.9 \pm 8.3$ \\
\hline \multicolumn{6}{|c|}{ Strain (segments; $\mathrm{n}(\%)$ ) } \\
\hline \multicolumn{6}{|l|}{ Preop } \\
\hline Normal & $5(71)$ & $129(85)$ & $9(60)$ & $86(61)$ & $32(43)$ \\
\hline Abnormal & $2(29)$ & $23(15)$ & $6(40)$ & $55(39)$ & $43(57)$ \\
\hline \multicolumn{6}{|l|}{ Postop } \\
\hline Deteriorated & $1(14)$ & $25(16)$ & $0(0)$ & $11(8)$ & $9(12)$ \\
\hline Unchanged & $4(57)$ & $89(59)$ & $11(73)$ & $79(56)$ & $31(41)$ \\
\hline Improved & $2(29)$ & $38(25)$ & $4(27)$ & $51(36)$ & $35(47)$ \\
\hline \multicolumn{6}{|c|}{ Transmurality (segments; n (\%)) } \\
\hline \multicolumn{6}{|l|}{ Postop } \\
\hline Normal (<1\%) & $7(100)$ & $142(93)$ & $9(60)$ & $82(58)$ & $43(57)$ \\
\hline$\geq 1 \%$ & $0(0)$ & $10(7)$ & $6(40)$ & $59(42)$ & $32(43)$ \\
\hline$>50 \%$ & $0(0)$ & $0(0)$ & $5(33)$ & $25(18)$ & $20(27)$ \\
\hline
\end{tabular}

Segmental analysis of strain $(\varepsilon)$ pre and post $\mathrm{PCl}$ and infarction transmurality post-PCI calculated for normal and abnormal PCI wall motion score index (WMSI) preoperatively, in turn related to the different outcomes postoperatively (deteriorated, unchanged and improved).

with chronic scar 9 months post AMI [39]. Additionally, Sjøli et.al. showed a correlation of 0.62 between global strain and infarct size measured within $3.5 \mathrm{~h}$ after revascularization [40]. Global strain showed a higher correlation with the size of myocardial scar compared with LVEF. This is in line with our results showing that LVEF has only a weak correlation with infarct size and mean transmurality (table 2). Ugander et.al. also confirmed a large variation in LVEF in relation to infarct size and concluded that infarct size cannot be used to predict LVEF [41]. The number of dysfunctional adjacent segments seemed to be a more important determinant on regional wall function than infarct transmurality [42]. This could be caused by extensive hibernation or a compensatory increase in wall motion in healthy parts of scarred ventricles.

\section{Regional measurements}

By averaging measurements from the three segment levels in each wall, regional measurements could be correlated with regional scar. This was done to allow a comparison of strain and wall motion scoring with the regional motion amplitude of the mitral annulus, which could easily be obtained from tissue Doppler velocities integrated over time ("tissue tracking"). We found a rather low correlation for regional MAM vs. transmurality, higher for regional strain and the highest for WMSI vs. transmurality.

\section{Segmental measurements}

Evaluation of wall motion is very important in the clinical setting but draw-backs are the subjectivity [35] and the extended learning curve for the physician. Strain has been proposed to identify acute ischemia [24] and to grade myocardial dysfunction $[21,32]$. In this study we hypothesized that strain could quantify left ventricular function in relationship to scar transmurality. However, we found a higher correlation between wall motion and scar transmurality compared with strain vs. transmurality, as well as displacement vs. transmurality, both preand post PCI. Despite the theoretical advantages of strain, visual assessment by three experienced observers performed better when predicting scar transmurality in both the acute and chronic settings. Displacement, correlated even more weakly than strain $(r=0.28$ pre, $r=$ 0.34 post). This is in line the finding of Skulstad et.al. who studied the relationship of strain and displacement for quantification of regional myocardial function [32].

\section{Myocardial area at risk}

To determine myocardial salvage, an initial measure of myocardial area-at-risk is required. Myocardial oedema determined with MRI and myocardial perfusion 
Table 5 Segmental analysis of wall motion score index (WMSI) pre and post $\mathrm{PCI}$ and transmurality post $\mathrm{PCI}$

\begin{tabular}{|c|c|c|c|c|c|c|}
\hline \multirow{2}{*}{$\begin{array}{l}\text { PrePCI strain } \\
\text { Follow-up strain }\end{array}$} & \multicolumn{3}{|c|}{ Normal } & \multicolumn{3}{|c|}{ Abnormal } \\
\hline & Deteriorated & Unchanged & Improved & Deteriorated & Unchanged & Improved \\
\hline $\mathrm{n}$ & 44 & 162 & 55 & 2 & 52 & 75 \\
\hline \multicolumn{7}{|l|}{ Strain (mean $\pm S D$ ) } \\
\hline Preop & $-21 \pm 5$ & $-17 \pm 4$ & $-15 \pm 3$ & $-1 \pm 4$ & $-6 \pm 5$ & $-4 \pm 6$ \\
\hline Postop & $-12 \pm 6$ & $-17 \pm 4$ & $-24 \pm 4$ & $7 \pm 6$ & $-8 \pm 5$ & $-16 \pm 6$ \\
\hline Post-pre-difference & $-6 \pm 3$ & $-6 \pm 3$ & $-7 \pm 4$ & $-1 \pm 1$ & $-3 \pm 3$ & $-4 \pm 4$ \\
\hline \multicolumn{7}{|l|}{ WMSI (mean \pm SD) } \\
\hline Preop & $1.4 \pm 0.5$ & $1.3 \pm 0.5$ & $1.4 \pm 0.4$ & $2.6 \pm 0.1$ & $1.9 \pm 0.7$ & $2.1 \pm 0.8$ \\
\hline Postop & $1.2 \pm 0.3$ & $1.3 \pm 0.4$ & $1.3 \pm 0.4$ & $2.6 \pm 0.1$ & $1.7 \pm 0.7$ & $1.6 \pm 0.6$ \\
\hline Post-pre-difference & $1.2 \pm 0.4$ & $1.1 \pm 0.4$ & $1.0 \pm 0.4$ & $1.0 \pm 0.0$ & $1.1 \pm 0.6$ & $1.4 \pm 0.5$ \\
\hline \multicolumn{7}{|c|}{ WMSI (segments; n (\%)) } \\
\hline \multicolumn{7}{|l|}{ Preop } \\
\hline Normal & $26(59)$ & $83(51)$ & $25(45)$ & $0(0)$ & $10(19)$ & $15(20)$ \\
\hline Abnormal & $18(41)$ & $79(49)$ & $30(55)$ & $2(100)$ & $42(81)$ & $60(80)$ \\
\hline \multicolumn{7}{|l|}{ Postop } \\
\hline Deteriorated & $1(2)$ & $8(5)$ & $5(9)$ & $0(0)$ & $7(13)$ & $1(1)$ \\
\hline Unchanged & $34(77)$ & $136(84)$ & $45(82)$ & $2(100)$ & $32(62)$ & $44(59)$ \\
\hline Improved & $9(20)$ & $18(11)$ & $5(9)$ & $0(0)$ & $13(25)$ & $30(40)$ \\
\hline \multicolumn{7}{|c|}{ Transmurality (segments; $\mathrm{n}(\%)$ ) } \\
\hline \multicolumn{7}{|l|}{ Postop } \\
\hline Normal $(<1 \%)$ & $40(91)$ & $130(80)$ & $44(80)$ & $1(50)$ & $27(52)$ & $41(55)$ \\
\hline$\geq 1 \%$ & $4(9)$ & $32(20)$ & $11(20)$ & $1(50)$ & $25(48)$ & $34(45)$ \\
\hline$>50 \%$ & $1(2)$ & $11(7)$ & $3(5)$ & $1(50)$ & $16(31)$ & $18(24)$ \\
\hline
\end{tabular}

Segmental analysis of wall motion score index (WMSI) pre and post PCl and infarction transmurality post $\mathrm{PCl}$ calculated for the different outcomes of strain ( $\varepsilon$ ) pre- $\mathrm{PCl}$, in turn related to the different outcomes postoperatively (deteriorated, unchanged and improved).

determined with SPECT have been used, mainly because imaging can be delayed for several days for MRI and for 6-8 hours in regard to SPECT. In the present study, we selected wall motion assessment, either visual or by tissue Doppler, because of its low cost, availability at bedside, and the possibility to perform assessment in immediate relation to the intervention. We found that both methods identified segments that were to develop scar transmurality in excess of $50 \%$. However, wall motion scoring performed better than strain measurement both in terms of detecting initially threatened segments and in avoiding false positive results. In total, $42 \%$ of threatened segments according to wall motion scoring developed significant myocardial scar. This result is in line with guidelines suggesting that the goal of acute infarct treatment is a final scar size $<40 \%$ of the initial risk area [12].

\section{Limitations}

The first echocardiographic examination was performed under difficult scanning conditions, while preparing the patient for acute PCI resulting in a compromised image quality. However, correlations were in the same range as for measurements performed at follow-up, when the imaging conditions were favourable. Strain measurements are known to be load dependent [19,43], which can have influenced measurements performed under the acutely unstable hemodynamic conditions of myocardial infarction. While velocity, displacement and strain obtained with tissue Doppler are angle-dependent, 2D-speckle tracking adds a second dimension to the scanning plane which reduces the influence of off-angle effects. Accordingly, speckle tracking MRI has shown higher values for peak longitudinal strain of healthy segments (about $-20 \%$ ) vs our tissue Doppler values (-17) [44]. In the present study, speckle tracking was not performed because the underlying gray scale frame rate in the colour tissue Doppler loops was too low to allow good quality tracking Tissue Doppler produces a strong signal from the myocardial wall also in difficult imaging conditions and was thus projected to produce a more stable result than visual assessment. But, in the post processing analysis, strain curves turned out to be sensitive to the placement of the ROI's as well as to shadowing from the lungs.

In this study we have used a 16 segment model of the left ventricle in favour of the newer 17 segment model proposed by AHA [45]. However, since the 16 segments are identical with those of the AHA model and 


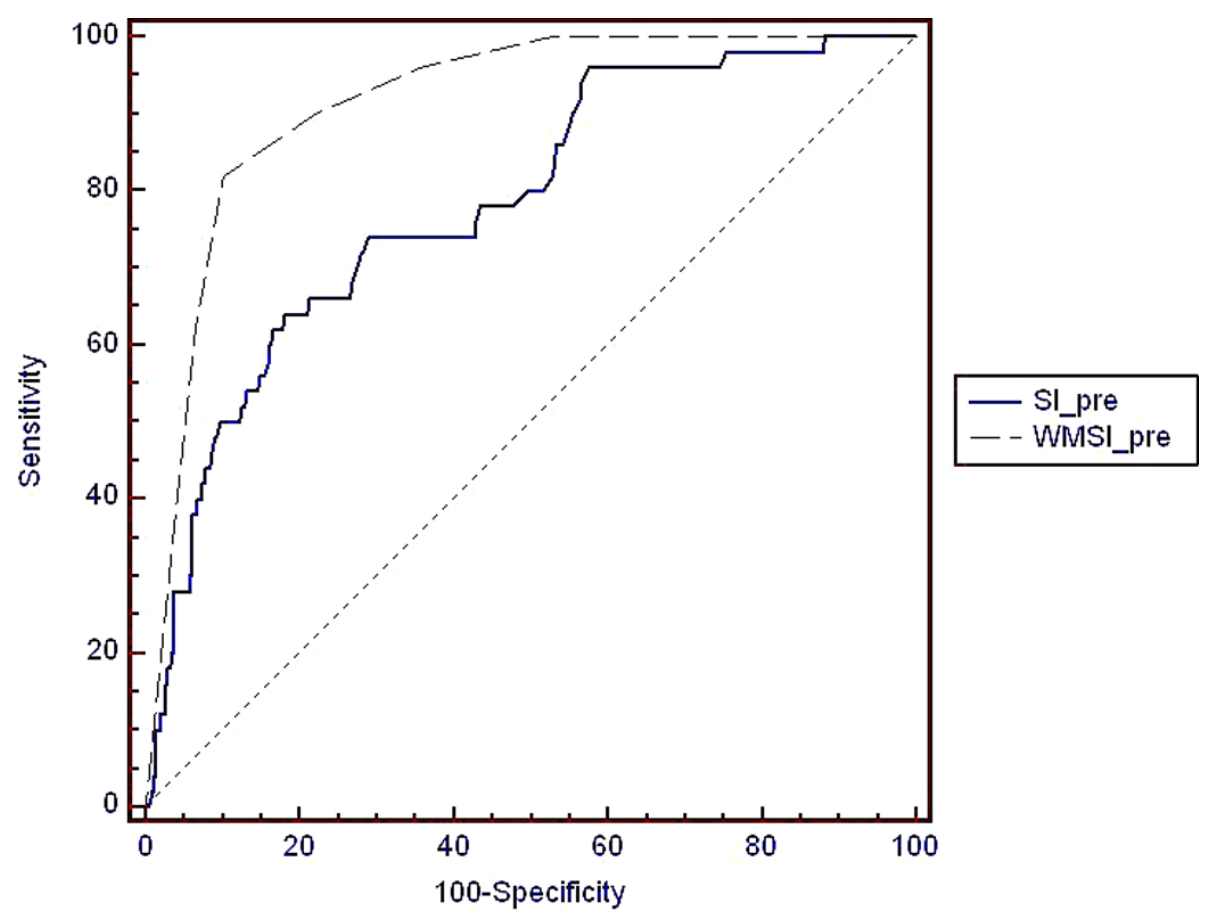

Figure 4 ROC curves for WMSI and strain vs transmurality $\mathbf{2 5 0} \%$. ROC-curves displaying the interrelationship between sensitivity and specificity for wall motion score index and strain vs. the detection of segments with a transmurality $\geq 50 \%$. Area-under-curve for WMSI is 0.92 and for strain $0.78, p<0.0001$. WMSI = Wall motion score index, $\mathrm{SI}=$ peak longitudinal strain

measurements were not performed on the apical cap, the model was not considered to have an influence on the result.

Registration (= aligning images from different studies) is a major problem when studies are performed on patients at different time points and with different modalities. However, WMSI, strain, displacement and infarct transmurality were all assessed in the long axis view and care was taken to align the imaging plane with that used for measuring transmurality.

\section{Conclusions}

Echocardiography, acutely performed while preparing patients for primary PCI, detected myocardial area at risk using two methods: subjective assessment of wall motion as well as objective measurement of deformation (strain). These measurements, repeated at follow-up 4-8 weeks later, correlated with the development of scar transmurality in excess of $50 \%$, which is considered to be the limit for the return of useful wall motion post intervention. Analysis based on receiver-operator-characteristics curves showed WMSI to be superior to peak longitudinal strain in this prediction. Thus, advanced technological analysis of wall motion did not contribute additional value compared with a careful visual assessment by an experienced observer.

\section{Funding}

This project was supported by Futurum - the academy for healthcare, Jönköping County Council, the Swedish Heart Lung Foundation, the Swedish Research Council, the Medical Research Council of Southeast Sweden, the Centre for Medical Image Science and Visualization, Linköping University Hospital, and the faculty of Linköping University.

Additional file 1: Gray scale 4-chamber view. Patient at follow-up, with thinning and akinesia in the distal part of the septum and in the apex.

Click here for file

[http://www.biomedcentral.com/content/supplementary/1476-7120-8-2S1.WMV ]

Additional file 2: Doppler strain imaging 4-chamber view. The same patient as above. The blue trace displays low and delayed peak longitudinal strain (5\%) from the apical septal segment while the yellow trace from the normal middle segment of the septum displays normal peak longitudinal strain at about 30\%.

Click here for file

[http://www.biomedcentral.com/content/supplementary/1476-7120-8-2S2.WMV ]

Additional file 3: Tissue tracking 4-chamber view. The same patient as above. Tissue tracking of the mitral annular excursion is somewhat low at $8.5 \mathrm{~mm}$ in both the septal and the lateral wall. It is not reduced in the septum despite the apical myocardial infarct.

Click here for file

[http://www.biomedcentral.com/content/supplementary/1476-7120-8-2S3.WMV] 


\section{Acknowledgements}

Johan Kihlberg and Margreta Hallgren for scanning patients, Elisabeth Logander for coordinating patient recruitment, and GE Healthcare for access to ultrasound scanner hardware.

\section{Author details}

'Department of Clinical Physiology, Ryhov County Hospital, Jönköping, Sweden. ${ }^{2}$ Center for Medical Image Science and Visualization, CMIV, Linköping University Hospital, Linköping, Sweden. ${ }^{3}$ Department of Clinical Physiology, Kalmar County Hospital, Kalmar, Sweden. ${ }^{4}$ Department of Medical and Health Sciences, Linköping University Hospital, Linköping, Sweden. ${ }^{5}$ Department of Medical and Health Sciences/CVM/Division of Cardiology, Linköping University Hospital, Linköping, Sweden. ${ }^{6}$ Department of Medical and Health Sciences/CVM/Division of Clinical Physiology, Linköping University Hospital, Linköping, Sweden.

\section{Authors' contributions}

LR performed a major part of all measurements and in writing the manuscript. PB participated in evaluating some of the patients and reviewed the manuscript. LB participated in the statistical analysis of the results and in writing of the manuscript. $\Pi$ participated in planning the study, was responsible for the angiographic evaluation and reviewed the manuscript. JE planned the study, investigated some of the patients, performed measurements and analyses and took a major part in writing the manuscript. All authors have read and approved the final manuscript.

\section{Competing interests}

The authors declare that they have no competing interests.

Received: 4 December 2009

Accepted: 11 January 2010 Published: 11 January 2010

\section{References}

1. De Luca G, Suryapranata H, Ottervanger JP, Antman EM: Time delay to treatment and mortality in primary angioplasty for acute myocardial infarction: every minute of delay counts. Circulation 2004, 109(10):1223-1225.

2. De Luca G, Suryapranata H, Zijlstra F, van't Hof AW, Hoorntje JC, Gosselink AT, Dambrink JH, de Boer MJ: Symptom-onset-to-balloon time and mortality in patients with acute myocardial infarction treated by primary angioplasty. J Am Coll Cardiol 2003, 42(6):991-997.

3. McNamara RL, Wang Y, Herrin J, Curtis JP, Bradley EH, Magid DJ, Peterson ED, Blaney M, Frederick PD, Krumholz HM: Effect of door-toballoon time on mortality in patients with ST-segment elevation myocardial infarction. J Am Coll Cardiol 2006, 47(11):2180-2186.

4. Cannon CP, Gibson CM, Lambrew CT, Shoultz DA, Levy D, French WJ, Gore JM, Weaver WD, Rogers WJ, Tiefenbrunn AJ: Relationship of symptom-onset-to-balloon time and door-to-balloon time with mortality in patients undergoing angioplasty for acute myocardial infarction. Jama 2000, 283(22):2941-2947.

5. Milavetz JJ, Giebel DW, Christian TF, Schwartz RS, Holmes DR Jr, Gibbons RJ: Time to therapy and salvage in myocardial infarction. J Am Coll Cardiol 1998, 31(6):1246-1251.

6. van't Hof AW, Liem A, Suryapranata H, Hoorntje JC, de Boer MJ, Zijlstra F: Clinical presentation and outcome of patients with early, intermediate and late reperfusion therapy by primary coronary angioplasty for acute myocardial infarction. Eur Heart J 1998, 19(1):118-123.

7. Christian TF, Schwartz RS, Gibbons RJ: Determinants of infarct size in reperfusion therapy for acute myocardial infarction. Circulation 1992, 86(1):81-90.

8. Ndrepepa G, Mehilli J, Schwaiger M, Schuhlen H, Nekolla S, Martinoff S, Schmitt C, Dirschinger J, Schomig A, Kastrati A: Prognostic value of myocardial salvage achieved by reperfusion therapy in patients with acute myocardial infarction. J Nucl Med 2004, 45(5):725-729.

9. Brodie BR, Stone GW, Cox DA, Stuckey TD, Turco M, Tcheng JE, Berger P, Mehran R, McLaughlin M, Costantini C, et al: Impact of treatment delays on outcomes of primary percutaneous coronary intervention for acute myocardial infarction: analysis from the CADILLAC trial. Am Heart J 2006, 151(6):1231-1238.

10. Brodie BR, Stuckey TD, Wall TC, Kissling G, Hansen CJ, Muncy DB, Weintraub RA, Kelly TA: Importance of time to reperfusion for 30-day and late survival and recovery of left ventricular function after primary angioplasty for acute myocardial infarction. J Am Coll Cardiol 1998, 32(5):1312-1319

11. Lundergan CF, Reiner JS, Ross AM: How long is too long? Association of time delay to successful reperfusion and ventricular function outcome in acute myocardial infarction: the case for thrombolytic therapy before planned angioplasty for acute myocardial infarction. Am Heart J 2002, 144(3):456-462.

12. Miura T, Miki T: Limitation of myocardial infarct size in the clinical setting: current status and challenges in translating animal experiments into clinical therapy. Basic Res Cardiol 2008, 103(6):501-513.

13. Madler CF, Payne N, Wilkenshoff U, Cohen A, Derumeaux GA, Pierard LA, Engvall J, Brodin LA, Sutherland GR, Fraser AG: Non-invasive diagnosis of coronary artery disease by quantitative stress echocardiography: optimal diagnostic models using off-line tissue Doppler in the MYDISE study. Eur Heart J 2003, 24(17):1584-1594.

14. Sheehan FH, Bolson EL, Dodge HT, Mathey DG, Schofer J, Woo HW: Advantages and applications of the centerline method for characterizing regional ventricular function. Circulation 1986, 74(2):293-305.

15. Kvitting JP, Wigstrom L, Strotmann JM, Sutherland GR: How accurate is visual assessment of synchronicity in myocardial motion? An In vitro study with computer-simulated regional delay in myocardial motion: clinical implications for rest and stress echocardiography studies. J Am Soc Echocardiogr 1999, 12(9):698-705.

16. Gilman G, Khandheria BK, Hagen ME, Abraham TP, Seward JB, Belohlavek M: Strain rate and strain: a step-by-step approach to image and data acquisition. J Am Soc Echocardiogr 2004, 17(9):1011-1020

17. Nesbitt GC, Mankad S, Oh JK: Strain imaging in echocardiography: methods and clinical applications. Int I Cardiovasc Imaging 2009, 25(Suppl 1):9-22.

18. Sutherland GR, Di Salvo G, Claus P, D'Hooge J, Bijnens B: Strain and strain rate imaging: a new clinical approach to quantifying regional myocardial function. J Am Soc Echocardiogr 2004, 17(7):788-802.

19. Urheim S, Edvardsen T, Torp H, Angelsen B, Smiseth OA: Myocardial strain by Doppler echocardiography. Validation of a new method to quantify regional myocardial function. Circulation 2000, 102(10):1158-1164.

20. Kowalski M, Kukulski T, Jamal F, D'Hooge J, Weidemann F, Rademakers F, Bijnens B, Hatle L, Sutherland GR: Can natural strain and strain rate quantify regional myocardial deformation? A study in healthy subjects. Ultrasound Med Biol 2001, 27(8):1087-1097.

21. Jamal F, Kukulski T, Sutherland GR, Weidemann F, D'Hooge J, Bijnens B, Derumeaux $G$ : Can changes in systolic longitudinal deformation quantify regional myocardial function after an acute infarction? An ultrasonic strain rate and strain study. J Am Soc Echocardiogr 2002, 15(7):723-730.

22. Kukulski T, Jamal F, D'Hooge J, Bijnens B, De Scheerder I, Sutherland GR: Acute changes in systolic and diastolic events during clinical coronary angioplasty: a comparison of regional velocity, strain rate, and strain measurement. J Am Soc Echocardiogr 2002, 15(1):1-12.

23. Ohara Y, Hiasa Y, Hosokawa S, Miyazaki S, Ogura R, Miyajima H, Yuba K, Suzuki $N$, Takahashi T, Kishi $K$, et al: Usefulness of ultrasonic strain measurements to predict regional wall motion recovery in patients with acute myocardial infarction after percutaneous coronary intervention. Am J Cardiol 2007, 99(6):754-759.

24. Kukulski T, Jamal F, Herbots L, D'Hooge J, Bijnens B, Hatle L, De Scheerder I, Sutherland GR: Identification of acutely ischemic myocardium using ultrasonic strain measurements. A clinical study in patients undergoing coronary angioplasty. J Am Coll Cardiol 2003, 41(5):810-819.

25. Kim RJ, Fieno DS, Parrish TB, Harris K, Chen E-L, Simonetti O, Bundy J, Finn JP, Klocke FJ, Judd RM: Relationship of MRI Delayed Contrast Enhancement to Irreversible Injury, Infarct Age, and Contractile Function. Circulation 1999, 100:1992-2002.

26. Mahrholdt H, Wagner A, A Holly T, Elliott MD, Bonow RO, Kim RJ, Judd RM: Reproducibility of Chronic Infarct Size Measurement by ContrastEnhanced Magnetic Resonance Imaging. Circulation 2002, 106:2322-2327.

27. Hillenbrand HB, Kim RJ, Parker MA, Fieno DS, Judd RM: Early assessment of myocardial salvage by contrast-enhanced magnetic resonance imaging. Circulation 2000, 102(14):1678-1683.

28. Kim RJ, Wu E, Rafael A, Chen EL, Parker MA, Simonetti O, Klocke FJ, Bonow RO, Judd RM: The use of contrast-enhanced magnetic resonance imaging to identify reversible myocardial dysfunction. N Engl J Med 2000, 343(20):1445-1453. 
29. Kitagawa K, Sakuma H, Hirano T, Okamoto S, Makino K, Takeda K: Acute Myocardial Infarction:Myocardial Viability Assessement in Patients Early Thereafter-Comparison of Contrast-enhanced MR Imaging with Resting 201 TI SPECT. Radiology 2003, 226:138-144.

30. Schiller NB, Shah PM, Crawford M, DeMaria A, Devereux R, Feigenbaum H, Gutgesell H, Reichek N, Sahn D, Schnittger l, et al: Recommendations for quantitation of the left ventricle by two-dimensional echocardiography. American Society of Echocardiography Committee on Standards, Subcommittee on Quantitation of Two-Dimensional Echocardiograms. $J$ Am Soc Echocardiogr 1989, 2(5):358-367.

31. Lang RM, Bierig M, Devereux RB, Flachskampf FA, Foster E, Pellikka PA, Picard MH, Roman MJ, Seward J, Shanewise J, et al: Recommendations for chamber quantification. Eur J Echocardiogr 2006, 7(2):79-108.

32. Skulstad H, Urheim S, Edvardsen T, Andersen K, Lyseggen E, Vartdal T, Ihlen $H$, Smiseth OA: Grading of myocardial dysfunction by tissue Doppler echocardiography: a comparison between velocity, displacement, and strain imaging in acute ischemia. J Am Coll Cardiol 2006, 47(8):1672-1682.

33. Heiberg E, Ugander M, Engblom H, Gotberg M, Olivecrona GK, Erlinge D, Arheden $\mathrm{H}$ : Automated quantification of myocardial infarction from MR images by accounting for partial volume effects: animal, phantom, and human study. Radiology 2008, 246(2):581-588.

34. Dahlberg G: Statistical methods for medical and biological students. London George Allen \& Unwin Ltd, 21940.

35. Hoffmann $R$, Lethen $H$, Marwick $T$, Arnese M, Fioretti P, Pingitore A, Picano E, Buck T, Erbel R, Flachskampf FA, et al: Analysis of interinstitutional observer agreement in interpretation of dobutamine stress echocardiograms. J Am Coll Cardiol 1996, 27(2):330-336.

36. Reisner SA, Lysyansky P, Agmon Y, Mutlak D, Lessick J, Friedman Z: Global longitudinal strain: a novel index of left ventricular systolic function. J Am Soc Echocardiogr 2004, 17(6):630-633.

37. Gjesdal O, Hopp E, Vartdal T, Lunde K, Helle-Valle T, Aakhus S, Smith HJ, Ihlen $H$, Edvardsen T: Global longitudinal strain measured by twodimensional speckle tracking echocardiography is closely related to myocardial infarct size in chronic ischaemic heart disease. Clin Sci (Lond) 2007, 113(6):287-296

38. Vartdal T, Brunvand H, Pettersen E, Smith HJ, Lyseggen E, Helle-Valle T, Skulstad $\mathrm{H}$, Ihlen $\mathrm{H}$, Edvardsen $\mathrm{T}$ : Early prediction of infarct size by strain Doppler echocardiography after coronary reperfusion. J Am Coll Cardiol 2007, 49(16):1715-1721.

39. Gjesdal O, Vartdal T, Hopp E, Lunde K, Brunvand H, Smith HJ, Edvardsen T: Left ventricle longitudinal deformation assessment by mitral annulus displacement or global longitudinal strain in chronic ischemic heart disease: are they interchangeable?. J Am Soc Echocardiogr 2009, 22(7):823-830

40. Sjoli B, Orn S, Grenne B, Vartdal T, Smiseth OA, Edvardsen T, Brunvand H: Comparison of left ventricular ejection fraction and left ventricular global strain as determinants of infarct size in patients with acute myocardial infarction. J Am Soc Echocardiogr 2009, 22(11):1232-1238.

41. Ugander $M$, Ekmehag $B$, Arheden $H$ : The relationship between left ventricular ejection fraction and infarct size assessed by MRI. Scand Cardiovasc J 2008, 42(2):137-145.

42. Ugander M, Cain PA, Perron A, Hedstrom E, Arheden $\mathrm{H}$ : Infarct transmurality and adjacent segmental function as determinants of wall thickening in revascularized chronic ischemic heart disease. Clin Physiol Funct Imaging 2005, 25(4):209-214.

43. Rosner A, Bijnens B, Hansen M, How OJ, Aarsaether E, Muller S, Sutherland GR, Myrmel T: Left ventricular size determines tissue Dopplerderived longitudinal strain and strain rate. Eur J Echocardiogr 2009, 10(2):271-277.

44. Maret E, Todt T, Brudin L, Nylander E, Swahn E, Ohlsson JL, Engvall JE: Functional measurements based on feature tracking of cine magnetic resonance images identify left ventricular segments with myocardial scar. Cardiovasc Ultrasound 2009, 7(53).

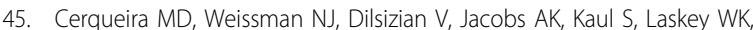
Pennell DJ, Rumberger JA, Ryan T, Verani MS: Standardized myocardial segmentation and nomenclature for tomographic imaging of the heart: a statement for healthcare professionals from the Cardiac Imaging Committee of the Council on Clinical Cardiology of the American Heart Association. Circulation 2002, 105(4):539-542. doi:10.1186/1476-7120-8-2

Cite this article as: Rosendahl et al:: Longitudinal peak strain detects a smaller risk area than visual assessment of wall motion in acute myocardial infarction. Cardiovascular Ultrasound 2010 8:2.

\section{Submit your next manuscript to BioMed Central and take full advantage of:}

- Convenient online submission

- Thorough peer review

- No space constraints or color figure charges

- Immediate publication on acceptance

- Inclusion in PubMed, CAS, Scopus and Google Scholar

- Research which is freely available for redistribution

Submit your manuscript at www.biomedcentral.com/submit
Biomed Central 